\title{
Notas sobre a relação família-escola na contemporaneidade
}

\author{
Notes on family-school relationship in contemporaneity
}

http://dx.doi.org/10.5007/2178-4582.2017v51n1p124

Fábio Kalil Souza

Instituto Federal de Educação, Ciência e Tecnologia de Sergipe, Aracaju/SE, Brasil

O desenvolvimento de qualquer ser humano pode ser concebida de forma intercontextual. Durante sua existência ele atravessa, mormente, dois inquestionáveis contextos de desenvolvimento: a família e a escola. Compreender como essas agências atuam, separadas e interconectadas, nesse processo de vir-a-ser do indivíduo é fundante para deseclipsar o assunto. A relação entre elas passa a ser o foco. Este artigo, de natureza teórica, apresenta um estudo não exaustivo da relação família-escola. A partir da revisão bibliográfica como metodologia, que inclui resultados de pesquisas nacionais e estrangeiras, o autor transita na temática descrevendo as principais contribuições das investigações. Concluiuse que a relação família-escola, tomada como imprescindível ao desenvolvimento dos sujeitos, é carregada de ambivalências, conflitos, assimetrias, contradições, mas também de cooperação, de parceria e de complementaridade de ações, a depender de como se dá o jogo inter-relacional entre os envolvidos e a presença de fatores socioculturais diversos.

Palavras-chave: escola; família; relação famíliaescola; desenvolvimento humano.
The development of any human being can be conceived in an intercontextual way. During its existence, it goes through, especially, two unquestionable development contexts: the family and the school. Understanding how these agencies operate both separately and interconnectedly in the process of coming-into-being of the individual is foundational to make this matter visible. The relationship between such agencies becomes the focus. This theoretical article presents a nonexhaustive study of family-school relationship. The methodology used is a literature review, which includes results from national and international research. The author moves on the topic describing the main contributions of the investigations. It was concluded that the family-school relationship, taken as essential to the development of the subject, is charged with ambivalence, conflicts, inequalities, contradictions, but also with cooperation, partnership and complementarity of actions, depending on how the game interrelation between those involved happens and the presence of various sociocultural factors.

Keywords: school; family; family-school relationship; human development.

\section{Fronteiras família-escola: um marco reflexivo}

Família, motor primário do desenvolvimento humano. Assim como as famílias, as escolas são embaladas nas transformações societárias, porquanto instituições histórico-culturais. A relação que estabelecem com as famílias não poderia ser concebida diferente, ou seja, a relação escola-famílias deve ser vista sob as transformações socioculturais em curso. Uma relação em que se interceptam duas instâncias socializadoras e formadoras em um território mais ou menos definido que é essa relação. Elas se mostram como espaço de intensa convivência social, com modos de sociabilidades peculiares, diversas entre si e por essas características são instituições heterogêneas marcadas pela diversidade e culturas (ROMANELLI, 2013). 
É fato consolidado e amplamente divulgado na literatura serem a família e a escola contextos privilegiados de desenvolvimento humano, conforme atestam estudos na sociologia e nas psicologias da família e do desenvolvimento, muito embora aspectos que interferem nessas duas agências, sejam como óbices a, sejam como promotores da relação, ainda careçam de mais aprofundamento e debate, o que evidencia a relação escola-famílias como um objeto científico lacunar, poroso e sempre aberto a novas questões, especialmente quando se considera, na intersecção com a escola, a rede de configurações familiares presentes contemporaneidade.

Mas como pode ser concebida tal relação? Na produção acadêmica não há uma preocupação em defini-la dada a irrelevância na exploração do tema, como também por se mostrar evidente na própria semântica dos termos. Na esteira sociológica, Silva (2010) a define como uma "relação entre culturas", as escolar e familiar, que podem conduzir a situações de continuidade ou de ruptura social, de aproximação ou de distância entre os sujeitos, de violência simbólica ou aculturação. Nesse lume, tal relação pode sedimentar ou atenuar as "desigualdades sociais e diferenças culturais" (p. 450), destaca o pesquisador. Para este trabalho, a rigor, tal relação é compreendida como uma fronteira de desenvolvimento humano, na qual escola e famílias intercambiam informações, experiências e aprendizagens, mostrando-se, na dinâmica da relação, um campo de possibilidades de os indivíduos - estudantes, familiares e profissionais da escola- se (re)educarem. Compreendo, portanto, tal relação como uma relação educativa. Nessa intersecção entre as duas agências, a criança e/ou o jovem se recobre como alvo de investimentos (materiais e imateriais); e na relação todos os processos e práticas para tais investimentos podem ser potencializados ou alargados.

Szymanski (2001), Oliveira e Marinho-Araújo (2010) sublinham que escola e família tem suas especificidades de funções e suas complementariedades, isto é, são agências ou estruturas sociais independentes e com objetivos distintos, e outros que se interpenetram, como o de formar seus sujeitosalvo (filhos/estudantes) para inserção crítica e autônoma no mundo social. As autoras ainda esclarecem que, tradicionalmente, compete à primeira, sobretudo, promover situações de aprendizagem do conhecimento cultural e historicamente organizado/sistematizado e de ampliar as possibilidades de convivência social (socialização secundária), ao passo que à família cabe a socialização primária de crianças, que inclui "o aprendizado de padrões comportamentais, atitudes e valores aceitos pela sociedade" (p. 101). Mas as pesquisadoras destacam que tais diferenças geralmente criam focos de tensão e conflitos. Embora sejam agências socializadoras distintas e com tarefas sociais bem delimitadas funcionalmente, elas compartilham também 
intenções (e práticas) convergentes, sendo a precípua (in)formar os sujeitos para vida sociocultural, política e econômica.

Cabe ressaltar, todavia, que com as transformações contemporâneas, a relação entre as duas agências educadoras imprime um tom volátil à delimitação de responsabilidades, tornando-as por vezes mais difusas e divididas, repousando à escola incorporar aquelas tradicionalmente sob o encargo das famílias, como, por exemplos, a formação ética e moral e a educação sexual; e do outro lado da moeda também acontece: as famílias assumindo atividades típicas da escola, como exercitar disciplina nos estudos ou mesmo prestar reforço nas tarefas/exercícios extraclasse (TANCREDI; REALI, 2001).

Um argumento que se impõe nessa assunção de funções mais específicas das famílias é a necessidade de melhor compreensão dos educandos partindo de suas vivências intrafamiliares para melhor ajustar práticas educativas institucionais, alargando as zonas de integração com as famílias, como esclarece Nogueira (2005):

Sob o argumento da necessidade de se conhecer o aluno para a ele ajustar a ação pedagógica, o coletivo de educadores da escola (professores, orientadores e outros) busca hoje ativamente e detém efetivamente as informações sobre os acontecimentos mais íntimos da vida familiar, como crises e separações conjugais, doenças, desempregos etc. A escola estende [não oficialmente] sua área de atuação em direção a terrenos reservados, no passado, à socialização familiar, como, por exemplo, a educação afetivo-sexual. A esse respeito, os sociólogos falam hoje de uma verdadeira redefinição da divisão do trabalho entre as duas instâncias. (p. 573)

Entretanto, nesse entrelaçamento relacional podem eclodir regiões de conflito, no qual papéis ou tarefas sociais são transferidos de uma a outra agência, sobrecarregando esta. Um exemplo que tipifica tal situação é quando famílias compartilham ou mesmo transferem à escola a responsabilidade de amparar emocionalmente seus filhos, que não é guardiã e parceira delas nesse processo. Por outro lado, famílias -sobretudo as pobres e com baixa escolaridade, em particular as monoparentais- parecem requerer esse apoio adicional como socorro em meio à predatória dinâmica de sobrevivência. Nesse contexto, marcado por um jogo relacional nem sempre harmônico, família e escola se complementam, cooperam mutuamente, mas também se divergem no conflito de funções não assumidas ou de interesses nem sempre consensuados, pendulando a relação em dois pólos. Assim, estudos não conclusivos terminam por consignar que a relação oscila entre a responsabilização/culpabilização e a colaboração e parceria. 
Essa questão pode ser abordada como uma expansão da esfera de influência da família sobre a escola (e vice-versa), como se o limite institucional entre elas abrisse brechas de interconexão; limites que servem para separar e, também, para conectar. Tal expansão do espaço de socialização tanto da escola quanto das famílias vem a contradizer a ideia de que a família vem delegar competências a outras agências, como a escola. Com base em Montandon (1987), Diogo (1998) adensa essa perspectiva explicando que

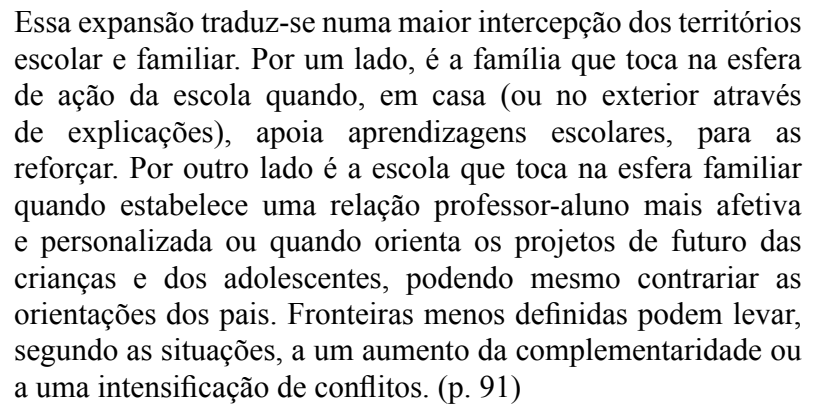

A essa mudança a mesma autora acrescenta, ainda em Montandon, outras de ordem das "mentalidades" de determinadas famílias, que tem a ver com: i) a ideia de participação e tomada de decisões na escola; ii) com uma disposição consumista "face aos serviços públicos (a escola é vista como uma instituição em que a família delega responsabilidades e, consequentemente, pretende que essa lhe preste contas)" e iii) pela busca de direitos dos indivíduos. Mudanças que explicam a progressiva necessidade "de que o maior espaço de intercepção dos papéis da escola e da família dê lugar à comunicação" (DIOGO, 1998, p. 91).

Ancorados em pesquisas sobre a interação família-escola, Polonia e Dessen (2005) apontam efeitos positivos para ambas, mas assinalam a dificuldade que é promovê-la em muitos contextos, permeados de conflitos e desencontros entre comunidades escolar e local. Behring (2003) põe em relevo a falta de conhecimento por parte de ambas sobre seus respectivos papéis -distinções e convergências- como agravante da interação, em particular acentuando desencontros entre pais e docentes. De fato, essa não clareza de atuações específicas de cada uma pode fechar as fronteiras da relação e aprofundar o abismo entre elas (famílias e escola).

Nessa discussão dos papéis entre escolarização e educação doméstica, é interessante a distinção observada por Libâneo (1998) no que se refere às práticas educativas como fenômeno social, portanto humano. Ao tratar da prática educativa intencional, ao autor explica que há duas modalidades: 
a educação formal e a não formal. A primeira diz respeito às atividades intencionais em que há direcionamento ou relações pedagógicas pouco estruturadas/sistematizadas, como acontece nos movimentos sociais, nos meios de comunicação de massa, em espaços culturais como cinema e museu, em locais de lazer, entre outros. A educação formal, como o termo sugere, é sistematizada e se caracteriza por ser institucionalizada e apresentar objetivos claros, métodos, currículo, procedimentos didáticos e conteúdos, podendo-se antecipar seus resultados. Sem que haja uma hierarquia entre elas, nota-se que a primeira modalidade é promovida nas famílias, ao passo que a segunda na escola como espaço privilegiado. Ambas se interpenetram e atravessam o processo de desenvolvimento do educando.

Em pesquisa realizada com pais e professoras, Oliveira (2004) destaca que embora no plano discursivo docentes valorizem a integração com as famílias, não se verificaram esforços da escola no sentido de atingir a desejada parceria. Por não se enquadrarem ao modelo nuclear de família, ainda conforme tal pesquisa, elas são estereotipadas e tachadas de "desestruturas" e responsabilizadas pelo fracasso escolar dos filhos. Elas, por seu turno, avaliam negativamente suas participações, muito embora desejassem mais efetivo envolvimento com a escola.

$\mathrm{Na}$ outra face da moeda, uma pesquisa realizada com as classes média e alta em escolas privadas, Fevorini (2009) constatou que os pais demonstramse envolvidos com a vida escolar dos filhos, não dispensado a elas a formação de valores e cuidados com a disciplina. Podemos inferir que a diferença desses resultados se pauta nas condições materiais de existência favoráveis de tais famílias e o acesso a bens culturais que elas proporcionam, o que conduz essas classes a aproximarem suas culturas às escolares e dialogarem com mesma linguagem, práticas e compartilharem valores em comum, e como resultado na ponta do processo contribui no acompanhamento e suporte à escolarização. A pesquisa também concluiu que a parceria entre escola e família pode ser alcançada mediante a busca de simetria e corresponsabilidade na relação.

Visualizando como paisagem de fundo essa divisão de responsabilidades de educação e socialização de crianças e jovens, bem como a interação que se estabelece entre escola e as multiformes famílias, campos de conhecimento como a sociologia, a psicologia, a educação, entre as principais debruçamse em estudos de diferentes dimensões da referida relação. Considerando variegadas perspectivas de análise, a relação escola-família pode ser enfocada sob duas lentes, ou melhor, distribuídos em dois blocos temáticos: o sociológico e o psicológico (OLIVEIRA, 2002), sumariamente descritos e analisados no subtópico seguinte. 


\section{Abordagens contemporâneas da relação família-escola}

$\mathrm{Na}$ abordagem sociológica a família é concebida como principal responsável pela formação moral e social do sujeito, a escola como instância de socialização secundária e a relação família-escola alimentada por determinantes culturais e ambientais, gerando por vezes conflito de finalidades: de um lado a família, preservando valores e práticas privados, que mormente destoam do que a escola pragmatiza em termos de organização e estratégias de socialização; do outro a escola, com sua organização, objetivos e valores coletivos, intencionada em disseminar sua lógica de operação, estabelecendo um modelo ideal de atuação familiar no processo de escolarização dos estudantes (OLIVEIRA; MARINHO, 2010).

Ainda nessa perspectiva, a escola parece se interessar na democratização do ensino e na regeneração da sociedade. Para cumprir tal missão amplia sua esfera de ação tomando sobre os ombros, se necessário, o encargo de substituir parcial ou totalmente as famílias em suas tarefas socializadoras. O estreitamento dessa relação demonstra ser conduzido de modo unilateral, no qual o contexto escolar exerce (determina?) poder diretivo sobre as famílias, apontando como elas podem educar seus filhos para que permaneçam e se desenvolvam na escola (OLIVEIRA, 2002).

Em seu olhar sobre a revisão de literatura, Dias (2009) sinaliza que os estudos sociológicos tendem suas pesquisas para as práticas educativas familiares em relação aos filhos, focalizando o modelo e caracterizando a relação que elas estabelecem com a escola. Em outro pólo, sob o prisma psicológico, a mesma autora percebe uma tendência em tocar em dimensões mais intrínsecas aos sujeitos, como suas percepções, suas representações e atitudes, seus desejos, seus padrões interacionais, entre outros. Todavia, sua caracterização dos estudos não dissocia em campos separados, posto que podemos encontrar aspectos sociológicos em pesquisas que ela caracteriza como psicológica e vice-versa. Em sintonia com sua compreensão, este trabalho aborda a relação escola-família envolvendo aspectos integrados, pois entendemos que não se exclui a possiblidade de componentes sociológicos em estudos psicológicos (nem o contrário).

No enfoque psicológico a família é vista como matriz de formação psicológica da criança e do jovem, a quem vislumbram uma referência de operar no mundo e encontram amparo afetivo, condição de existência que será tomada como elo que conecta rendimento escolar e dinâmica familiar. O enfoque, assim, é uma tentativa de explicar adequado desempenho escolar ou seu fracasso, responsabilizando o contexto familiar por quaisquer desses resultados. O plano afetivo ganha relevância não somente para compreender o fracasso escolar, como também a integração escola-família (OLIVEIRA, 2002). Sem 
negar a presença de elementos sociológicos, esta pesquisa se insere na abordagem psicológica por se investigar percepção humana.

Essas abordagens têm subsidiado investigações teóricas e empíricas nas diferentes faces que envolvem a integração escola-família, como: i) as recentes formas de envolvimento de familiares com a escola, ii) as implicações educativas dessa integração, iii) o (in)sucesso escolar a partir de elo entre socialização escolar e socialização familiar, iv) subsidiado estudos das representações dos diferentes segmentos escolares (professores, estudantes etc) ou dos familiares sobre a relação escola-família, escolaridade e classe-social, sobre função da escola e outras representações, como também v) o confronto delas no contexto da referida integração, entre as principais.

Uma perspectiva teórica passível de ser aplicada na compreensão da articulação escola-família e adotada neste trabalho é a ecológica (BRONFENBRENNER, 1996). Tal abordagem concebe que a família como um ecossistema micro onde a criança dá os primeiros passos na sua jornada de desenvolvimento, sendo afetada por diferentes esferas de influência, contidas umas nas outras. Nessa ótica interpretativa, família e escola representam o microssistema; e o sistema educativo e a sociedade global como o macrossistema. A socialização da criança e do adolescente resulta da ação complementar entre escola e famílias de um lado, e do outro entre essas agências e influências externas derivadas do macrossistema.

No referente modelo teórico de desenvolvimento humano, a pessoa (estudante) interage em contextos diversos (família, escola e grupos sociais) numa escala de tempo que compreenderia a duração das interações (elemento tempo) e sob condições adequadas em dado momento histórico. A forma como esses elementos (pessoa, contexto, tempo e condições) se articulam tem efeito desenvolvimental sobre o sujeito, cujo sucesso na trajetória escolar, a meu ver, é proporcional à convergência de influência daqueles sistemas em benefício do educando, isto é, quanto mais amplo for a influência da escola e da família, de forma conectada e coordenada, maior a possibilidade de desenvolvimento.

Endossando essa perspectiva desenvolvimental, Hernandez (2005) argumenta que o desenvolvimento é fruto das influências de diferentes contextos (sistemas) nos quais o indivíduo interage. A partir de tal compreensão, escola e família são mutuamente influentes e complementares. Além disso, é relevante pontuar que a influência dessa relação impacta o educando, e por essa razão é mister a escola, ao pensar/planejar/construir suas práticas, ter em consideração outros contextos de desenvolvimento, como (e principalmente) a família. E os mecanismos de aproximação e de relação com as famílias precisam coadunarse aos modos de organização e dinâmicas internas dos dois contextos. 
Essa proposta, dada sua concepção sistêmica, mostra-se mais próxima de um estudo interdisciplinar tanto da família quanto de sua relação com a escola. $\mathrm{Na}$ abordagem ecológica percebo um movimento de idas e vindas em diferentes territórios de conhecimentos: nesse processo -como referencial de análise- há um deslocamento da visão sociológica sobre esfera macro da relação, para a captura de nuances da micro- esfera, que envolve o cotidiano escolar, as dinâmicas familiares, as representações do sujeitos, enfim, uma tomada do fenômeno sob olhares simultâneos (sociologia, psicologia, antropologia etc), o que pode levar uma compreensão refinada da relação escola-famílias.

\section{Como se entende a relação, a definição dos papéis dos agentes e os benefícios da relação}

A relação escola-famílias é um fenômeno multifacetado, histórico e culturalmente situado, assim como o são as agências envolvidas. Uma relação, portanto, que se dinamiza junto às transformações sociais que afetam a família, a escola e os agentes ligados a ela. Relação ambivalente. Ambivalente porque é permeada de: conflitos, relações de poder, mas também de complementaridade, colaboração e parceria; vivenciada por distanciamentos e aproximações, continuidades e descontinuidades. Nesse sentido ela pode ser compreendida numa perspectiva de fronteira (IANNACONNE; MARSICO, 2012), sem a ideia de limite que as separa, mas como zonas porosas de ligação, onde fluem de ambos os lados informações, significados, experiências de aprendizagem.

Escola e família, na modernidade, tem se intensificado em seus diálogos, imbricando-se cada vez mais na complexa tarefa de educar, e a "presença dos pais no recinto escolar e sua participação nas atividades torna-se cada vez mais comum" (NOGUEIRA, 2005, p. 575). A autora atribui esse interesse e participação familiares à disseminação de discursos de especialistas sobre educação de crianças e adolescentes e o aumento do nível de escolaridade da população. Do seu pólo, a escola se autoriza a interiorizar-se mais nas famílias, não se limitando à formação intelectual dos estudantes, estendendo seu campo de ação aos aspectos corporais, morais, afetivos, tradicionalmente vistos sob responsabilidade familiar. Percebe-se uma evolução consubstanciada na redefinição de papéis, levando ao desenho de fronteiras não claramente delimitadas. Fronteiras não definidas que podem levar ora a complementaridade de ações ora a conflitualidade.

Direcionando a lupa nesse foco de análise, família e escola se apresentam como estruturas sociais indispensáveis no desenvolvimento de pessoas, podendo, paradoxalmente, atuar como propulsora ou inibidora da evolução 
física, intelectual, social e emocional do indivíduo. Imbricadas em experiências educacionais diferenciadas, crianças e adolescentes desenvolvem pesquisas, leituras orientadas, atividades em laboratório, cumprimento de exercícios didáticos, entre outras atividades pedagogicamente mais sistematizadas comparadas às vivenciadas nas famílias e que atendem demandas sociais, psicológicas deles. Logo, a escola é outro contexto em que o indivíduo pode ampliar seu repertório de conhecimento (MARQUES; SIGOLO, 2012, REGO, 2003, POLONIA; DESSEN, 2005, SZYMANSKI, 2001).

Pesquisas (COSTA, 2003, FONSECA, 2003, MARQUES; SIGOLO, 2012, OLIVEIRA; MARINHO-ARAÚJO, 2010) tem apontado resultados profícuos da interlocução escola-família, em particular quando o projeto pedagógico da escola oferece janelas de participação das famílias e vetoriza os papéis diferenciados de ambos contextos nos processo de desenvolvimento do educando; projeto que permite a ações conjuntas complementares, como também aquelas singulares, específicas de cada espaço educacional. Nessa compreensão, ao passo que a escola incentiva e orienta uma formação mais ampliada do saber científico e cultural, a família privilegia a construção/ internalização de valores e de crença, e por conseguinte o desenvolvimento e aprendizagem do indivíduo se processam de forma coordenada.

É uma relação que se processa por meios formais e informais no seu cotidiano. E para além dos modos tradicionais de comunicação como a participação na reunião de pais e mestres e de reuniões com equipe gestora, diversificam-se os mecanismos de comunicação e interação, concretizados em jornadas envolvendo os pais, palestras e cursos voltados à comunidade local, projetos pedagógicos que a envolvem, contatos telefônicos, via web e corpoa-corpo (individualização da relação), além da criança e do adolescente, que, para Perrenoud e colaboradores (2005), é a melhor forma de comunicação. Relevante sublinhar, porém, que embora se multipliquem e se diversifiquem esses modos, a participação das famílias, sobretudo nos processos decisórios da escola, é proporcional ao domínio do capital cultural e socioeconômico que elas detêm, como atesta Davies citado por Diogo (1998, p. 103), o que não é realidade para maioria da população pobre.

Outra nota premente: as relações entre família e escola apresentam padrões de modos de interação singulares, os quais é importante serem identificados e analisados no intuito de melhor compreender aspectos gerais da relação e particulares de cada ambiente. Estudos tem demonstrado os benefícios potenciais dessa integração para o desenvolvimento sociocultural, afetivo e cognitivo dos estudantes; a qual deve ser pensada considerando os contextos culturais da família e da escola (crenças, valores, particularidades ambientais etc), valendo-se então de estratégias para construir as relações, alcançando 
assim a concretização de objetivos comuns (BACKER, 1999, CARVALHO, 2000, EPSTEIN, 1986, MARQUES; SIGOLO 2012).

\section{Como é percebida a relação, o confronto de culturas e os conflitos e barreiras}

Todavia, embora os estudos apontem como benéfica a supramencionada relação, ela não se dá mormente sem conflitos, diferenças na relação de poder, na qual a escola com frequência se coloca no topo em função de dominar mais o saber científico em contraste com famílias pobres e com reduzida escolaridade, relação portanto assimétrica sobretudo em escolas públicas, ainda que de modo sutil. Nessa perspectiva, Ribeiro e Andrade (2006) e Thin (2010) analisam a dinâmica de dominação de escolas públicas junto às famílias populares, na qual a cultura escolar se mostra prevalente na socialização dos sujeitos; domínio que atinge sua eficácia pautada na crença de legitimidade conferida pela instituição aos educadores e às práticas ali promovidas. O segundo autor elucida que a legitimidade desses se ancora em seus saberes escolares, na suposta autoridade pedagógica e na competência educativa consignada pela formação. Dessa forma, as culturas das famílias não são valorizadas e "entregam aos educadores a escolarização de seus filhos, reconhecendo ao mesmo tempo a legitimidade dos agentes e a sua própria incompetência [para educar]" (p. 68).

Reconhecemos todo o elenco de vantagens que a escolarização oferta a todas as classes sociais, tais como: lugar de aprendizagem e desenvolvimento, de sociabilidade, de potencial inclusão e/ou ascensão social (esta sobretudo para as classes médias), instituição portadora privilegiada de oferecer à sociedade elemento ímpar no desenvolvimento de uma nação: a educação formal, entre as principais; mas também se percebe que a escola pode representar espaço de exclusão social quando não abarca e/ou valoriza a pluralidade cultural, étnico-racial, religiosa e social dos educandos e dos profissionais envolvidos; é valioso olhar criticamente a escola quando arbitrariamente impõe sua cultura (valores, crenças etc), sua forma de organização, funcionamento e de relacionamento com as famílias de modo hierarquizado e formatado em padrões; quando trata a educação como produto (sentido mercadológico) e se torna tributária ao negar uma formação plena dos sujeitos, focalizando prioritariamente a intelectual; escola que se diz democrática, mas alimenta práticas autoritárias sutilmente disfarçadas, lugar onde os pais não a vê "como sendo deles, mas um espaço do outro e sobre o outro, o qual não tem direito, e por isso, somente podem se aproximar quando autorizados, convidados ou convocados" (NEVES, 2014, p. 174). 
Olhar criticamente as famílias também é necessário. Muitas são embaladas pelo espírito consumista e individualista de nosso tempo, deixando sobre os "ombros" escolares toda a tarefa de educação dos filhos, ignorando que esta é primeiramente promovida no ambiente familiar ao priorizar um viver ético e cidadão, incentivando também o interesse pelos estudos; ao passo que a educação formal compete à escolarização, diminuindo uma sobrecarga de responsabilidades que a escola nem sempre sustenta. As classes pobres assumem uma atitude consumista em relação aos serviços educacionais do Estado, porém não dão contrapartida citada acima. Às camadas médias da população especificamente convém uma postura mais crítica e ampla ao que se espera da formação de seus filhos e menos subserviente à logica de mercado, cujo propósito de fundo é aprovação concursos vestibulares ou equivalentes, e não prioritariamente uma formação plena dos sujeitos. Para ambas as classes, portanto, convém: a) disposição menos consumista e mais interessada no modelo de educação que prepare seus filhos para este tempo; b) interesse pela relação escola-família com ações cooperativas e c) assunção de atribuições primárias que cabem à família.

Outro relevante aspecto a sublinhar consiste nas relações humanas. As pessoas são a principal substância da articulação família-escola. Professores, pais e equipe pedagógica dialogam, permutam sentidos e significados, seja nos encontros pessoais seja via documentos. Ainda vale frisar que a relação, como movida por pessoas, não é estática/permanente, mas se (re)constrói ao longo do tempo, daí o desafio de criar novos mecanismos, de a própria escola reinventar-se na relação, de revê-la dentro do dinamismo social.

Em seus estudos, Montandon (1987) citado por Diogo (1998) contata que esses diferentes segmentos que permeiam a escola se diferenciam em suas representações e atitudes -por vezes contraditórias e ambíguas- no tocante à tal articulação, tornando-a mais complexa. À guisa de exemplo, docentes apresentam visão negativa dos pais de classe pobres considerando-os difíceis de se relacionar em função de seus modos de vida e características, contudo mostram-se dispostos a socorrer os pais na desafiadora tarefa de envolverse na escolarização dos filhos. Também mencionado por Diogo (1998), num estudo lusitano realizado em escola secundária, Afonso (1993) identifica representações contraditórias entre pais pobres e docentes: estes percepcionam os pais pouco participativos e responsáveis pela anêmica relação com a escola; contudo, ao invés de promover estratégias de aproximação deles com a instituição, esses profissionais receiam o envolvimento crítico dos pais, que se consideram interessados na relação e no que acontece na escola.

Implodindo com a percepção negativa de professores acerca do envolvimento dos pais, Paixão (2007) identifica interesse destes sobre a 
escolarização considerando-a como um trampolim para ascensão social. Nessa compreensão a ausência dos pais na escola não significaria necessariamente indiferença com a relação, mas o interesse assumiria formas menos públicas como acompanhamento do desempenho no lar, fornecimento de materiais didáticos e ambiente familiar favorável para estudos, orientação vocacional com especialistas, enfim, mobilizando todos os recursos acessíveis para potencializar a escolarização. Nota-se aqui a intercepção de fronteiras entre escola e famílias sem que haja o encontro físico e um local/espaço.

Como detentora e especializada na transmissão de saberes historicamente organizados e distribuídos no currículo, a escola pode tomar à frente no que concerne a orientação das famílias -em especial as pobres- na educação dos filhos, à criação de mecanismos de aproximação delas considerando suas especificidades e dinâmicas e ao robustecimento da relação, dissolvendo dúvidas quanto aos objetivos, filosofia, valores, normas e regras da instituição, o que em potência pode auxiliar famílias, mesmo as de baixa escolaridade, a melhor compreender suas lógicas de organização e funcionamento, e assim interagir de modo mais fluido e produtivo. Haveria, portanto, uma demanda por parte das famílias -sobretudo na escola pública- de capacitação para conhecer a escola e melhor apoiar seus filhos; capacitação que ela ainda não conseguiu dar contar. (LAHIRE, 1997 apud NEVES, 2014).

Releva assinalar, entretanto, que estudos indicam resultados desfavoráveis quando a relação é predominantemente assimétrica devido à distância entre a cultura escolar e as das famílias (pobres e com baixo domínio da cultura geral), podendo leva-las a situações de constrangimento e por conseguinte conflitos. Portanto, ainda que represente uma proposta carregada de boas intenções, a articulação escola-família é controversa e eivada de aspectos adversos. Uma relação passível de empobrecimento de significados e mútua colaboração se não forem tratados devidamente cada aspecto e os papéis que se complementam e outros que são exclusivos, atenuando a possibilidade de distanciamento e não-relação (que é um tipo de relação) entre famílias e escola (RIBEIRO, 2004, SILVA, 2003). Em crítica à abordagem da escola em convocações e reuniões com famílias pobres, Neves (2014) observa:

\footnotetext{
Embora os pais valorizem as convocações escola, por eles interpretadas como indicação de cuidado com os filhos, a forma como as práticas da escola são desenvolvidas faz que estas funcionem como armadilhas psicológicas para as famílias. Isso acontece porque as práticas, em vez de oferecerem uma experiência positiva, são desenvolvidas numa atmosfera negativa decorrente da agenda da escola nas reuniões, predominantemente para tratar situações problemáticas ( $\mathrm{p}$. 171).
} 
Essa conduta cria uma atmosfera negativa entre os sujeitos, em particular os pais, constrangendo-os publicamente, e desconsideram o fato de eles não disporem de tempo e, a rigor em famílias pobres, da devida escolaridade para subsidiar os filhos.

Não podemos deixar de lado uma das barreiras mais recorrentes, além da acima citada, que dificulta a relação contínua de famílias pobres com a unidade de ensino: a falta de tempo dos pais em função da jornada de trabalho, sobretudo para famílias monoparentais lideradas por mulheres, as quais tem se institucionalizado na sociedade contemporânea. Situação que move professores a considerarem as famílias ausentes e desinteressadas tanto na relação quanto na formação dos filhos e, como um efeito colateral dessa percepção, o surgimento de conflitos entre pais e professores. Estes exigem uma presença familiar que muitas vezes não é possível satisfazer, e as famílias são constrangidas e se vem cobradas por eles. Os profissionais passam a valorizar mais as presenças das famílias das classes médias, cujo capital simbólico (BOURDIEU, 1992), permite-lhes alinhar-se à cultura escolar e participar dos processos decisórios. Estabelece-se, quanto às famílias pobres, uma pseudo-simetria na relação, instaurando uma suposta isonomia camuflada pelo discurso democrático (RIBEIRO, 2004; SANTOS, 2001).

\section{Algumas (in)conclusões sobre a relação escola-família}

Família e escola são indubitavelmente espaços sociais de convivência, aprendizagem e desenvolvimento humano, cada uma com suas especificidades estruturais, funcionais e de organização. Porém apresentam como ponto de encontro, como objetivo comum a formação dos indivíduos (EPSTEIN, 1986, OLIVEIRA; MARINHO-ARAÚJO, 2010, SILVA, 2003). Nesse prisma, eles não podem ser vistos de modo fragmentado dentro dos processos de formação e desenvolvimento promovidos por ambas agências, mas holístico, com responsabilidades incumbidas a cada uma e portanto intransferíveis; e outras nas quais o esforço coordenado se faz necessário. Em suma: família e escola são contextos singulares de desenvolvimento, como também mutuamente complementares.

No tocante às mudanças sociais em curso envolvendo a família contemporânea, a pesquisa empírica tem registrado redução na taxa de fecundidade (o que resulta em menor prole), franco crescimento na taxa de separações e divórcios seguidos de ampliação das uniões consensuais não legalizadas e do aumento da famílias chefiadas por mulheres (monoparentais femininas), ingresso expressivo dessas no mercado de trabalho, busca de minorias sociais como gays e lésbicas pela legalização do casamento entre 
homoafetivos, expansão também de configurações familiares como as recompostas/reconstituídas, as de pais sem filhos por opção e as ampliadas (parentes se unem ao arranjo nuclear), sem esquecer as famílias patrifocais. Todas essas estruturas familiares conduz à conclusão, pelo menos ao nível dos modos de organização, que não há família, mas famílias, e nessa visão concordo com Romanelli (2013) que a análise da relação entre famílias e escola abarca compreender suas composições e modos de vida.

Conquanto a escola seja instituição privilegiada na oferta de formação acadêmica/intelectual, a formação desse sujeito é mais ampla a ponto de abarcar aprendizagens de competências sociais para convivência e de valores e hábitos socialmente consensuados, que tradicionalmente tem sido delegados às famílias. Sem que se esquivem desse papel que tem muito a ver com construção das subjetividades dos sujeitos, elas não são as únicas competentes, mas podem contar com a cooperação das escolas, afinal vivese uma sociedade fortemente marcada (e influenciada) pela escolarização, e desta dependem as famílias das mais diferentes classes sociais para inclusão e/ou ascensão social de seus filhos.

No jogo relacional entre família e escola, estudos indicam efeitos colaterais quando esta transfere responsabilidades para famílias pobres e com baixa escolaridade, que, em geral, não se veem capacitadas para cumpri-las em consonância com as expectativas da escola, posto que sua cultura refrata a das classes dominantes (BOURDIEU, 1989), deixando tais famílias em desvantagem na relação. Embora na experiência da escolarização no mundo ocidental a escola ceda mais espaço às propostas da classe média-mormente é com esta que a escola tem afinidade em dialogar, negociar e planejar-, é imprescindível que na relação sejam valorizadas as diferentes culturas familiares na tentativa de se promoverem estratégias mais eficazes de aproximação. Ao contemplar diferentes famílias, a escola estará considerando-as em suas especificidades sociais, de natureza/estrutura e dinâmicas tanto isoladamente quanto em processo de relação com a escola. Além disso, compreenderá que as famílias estão em processo de mudança e é no dinamismo das transformações sociais que se (re)constrói a relação.

Todavia, o que pesquisas sobre a relação entre escola e famílias tem demonstrado, em particular acerca da polarização na relação de poder entre elas, é que a escola comumente centraliza o poder e descentraliza as responsabilidades, tornando assimétrica a relação.

Os estudos também tem revelado que embora pais e docentes alimentem interesses em comum centrados no estudante, seus significados em torno da relação família-escola apontam para desconhecimento pleno de seus 
papéis nela, além de nem sempre se acordarem o que se expecta do outro (BHERING, 2003, NEVES, 2014, SÁ, 1997). Seja qual for a classe social, os pais esperam uma escola aberta à sua participação, contudo não esperam sentirem-se obrigados a comparecerem sempre na escola, o que pode ser percepcionado, pelos professores, como desinteresse e apatia no tocante à educação dos filhos, dando um tom preconceituoso ao julgarem as famílias despreparadas e "desestruturadas". De seu lado, paradoxalmente, a escola tem se mostrado pouco acessível e castradora da participação familiar - esta participa até o limite estabelecido pela escola-, levando a instituição assumir posturas tuteladoras e paternalistas em relação à família (NEVES, 2014, SILVEIRA; WAGNER, 2009).

Como toda relação que envolve humanos, a que se dá entre escolafamílias não está incólume a barreiras (sutis ou explícitas), que entre outras as pesquisas apontam: i) o (pré)conceito de família "desestruturada" pela escola; ii) a censura e acusação dos professores de que as famílias transferem suas responsabilidades para escola; iii) a condição sociocultural de pais que não conseguem atender demandas da escola, a qual os leva a situações de constrangimento; iv) a falta de tempo e/ou interesse dos pais para acompanhar o desenvolvimento escolar dos filhos; a assimetria da relação, na qual a escola é dominante, mormente prevalecendo seus interesses e projetos; v) a ausência de plena clareza de papéis no processo de interação, além de problemas na ordem de comunicação entre elas; vi) o limitado poder de voz concedido às famílias pobres, que lhe restam seguir as conveniências e ditames da escola e vii) conflitos na relação pais-professores (OLIVEIRA, 2004, SANTOS, 2001, SILVA; CAVALCANTE, 2012). No centro dos estudos sobre integração família-escola, professores e pais protagonizam diferentes práticas e percepções sobre ela, influenciando fortemente como se relacionam. Noutras expressões: a forma como cada família percebe a escola e sua relação com a mesma, e também como o professor percebe a relação e a família fora dela interfere no pensar e agir de cada um(a), isto é, as percepções influenciam poderosamente o comportamento deles na e sobre a relação. Se ambos mantem expectativas positivas, tenderão a agir de maneira favorável, auxiliando-se reciprocamente. Caso contrário, presumivelmente evitarão aproximar-se e desejar a relação, podendo surgir zonas tensão e conflitos.

Tratar de integração escola-família é também tratar de relações humanas. Nelas cada pessoa, seja da escola, seja da família, tem em aberto um campo simbólico para revelar como pensa, sente e age...como se produz e se organiza na cultura em que vive, exteriorizando-a na relação. É possível inferir, ainda, que as pessoas não são as mesmas em todas as relações e agem de determinada forma a depender da relação em que estão envolvidas (FRANCO, 2005), 
podendo alternar entre competição e cooperação, harmonia e conflito, rivalidade e parceria, enfim, sentimentos e ações ambivalentes que perpassam as relações entre sujeitos singulares na forma de interpretar e compreender o mundo. Entendo que os profissionais da escola não podem deixar de lado os detalhes dessas relações, que muitas vezes a torna única, sobretudo ao lidar com aqueles que enfrentam situações de sobrevivência adversas e se mostram socialmente vulneráveis. A relação escola-famílias produzirá resultados positivos se, a despeito das diferenças dos envolvidos, suas ações e interesses forem orquestrados em direção aos objetivos comuns, o que não significa ausência de conflitos, omissões, desentendimentos, contradições, elementos próprios das relações humanas.

Além disso, circunstâncias contraproducentes entre elas podem ser dissolvidas mediantes diálogos com as famílias. Diálogos interdisciplinares sem fronteiras que podem prevenir ou atenuar situações de conflito e violência na escola. Apresentando um dado novo na pesquisa da relação família-escola, Neves (2014) constatou -a partir das narrativas de docentes e pais- que a violência passou de problemática social a elemento vivo dentro da relação. Os primeiros descrevem os discentes "como vetores da violência e da insegurança do espaço escolar" (p. 176); ao passo que os pais, para além de espaço de educação, percebem a escola com ambiente perigoso onde os filhos estão vulneráveis, e ainda para eles a prole não é responsável pelo trânsito de violência e drogas que ali flui, devendo a escola protegê-los.

Como uma equação difícil de ser resolvida, a relação escola-famílias tem sido marcada por um fluxo dinâmico de aproximações e distanciamentos, ora de cooperação ora de oposição, de assimetria, ora de inter-relação complementar ora de tensão no processo de escolarização, como apontam os estudos apresentados neste trabalho, cuja revisão de literatura não se pretendia exaustiva, mas evidenciou a necessidade de novas investigações, inclusive no contexto do ensino profissionalizante.

Assim, buscou-se apresentar um panorama sobre o tema sem a intenção de fincar certezas teóricas, mas pelo contrário, este estudo representa um esforço para informar e suscitar incertezas e questionamentos a partir do que foi produzido, deixando perguntas em aberto: no âmbito das relações interpessoais, quais práticas e processos sociais podem imprimir maior vitalidade à relação escola-família? Como esta afeta as práticas educativas familiares? Afinal, existe uma fronteira que define/limita os papéis de cada agência na relação? Como conceber tal relação no contexto da sociedade capitalista? As distintas configurações familiares tem afetado a relação com a escola? Caso sim, em que aspectos? Que contraste pode ser feito entre a relação escola-família no Ensino Fundamental e no Ensino Médio? Haveria diferenças? Quais? A partir 
da proposta da teoria biecológica, como o macrossistema influencia a relação escola-família, em particular o sistema educacional do Estado ou do país? Entre outras questões.

\section{Referências}

AFONSO, N. A participação dos encarregados de educação na direcção das escolas. Revista Inovação, Campinas, v. 6, n, 2, p. 131-155. 1994.

BACKER, J. A. Teacher-student interaction in urban atrisk classroom: Differential behavior, relation quality and student satisfaction with school. The Elementary School Journal, Chicago, v. 100, n. 1, p. 57-70, 1999.

BOURDIEU, P. O poder simbólico. Rio de Janeiro: Bertrand, 1989.

BHERING, E. Percepções de pais e professores sobre o envolvimento dos pais na educação infantil e ensino fundamental. Contrapontos, Itajaí, v. 3, n. 3, p. 483-510, 2003. Disponível em: $<$ http://www6.univali.br/seer/index.php/rc/article/view/742 $>$. Acesso em 17 de agosto de 2014.

BRONFENBRENNER, U. A ecologia do desenvolvimento humano: experimentos naturais e planejados. Porto Alegre: Artes Médicas, 1996.

CARVALHO, M. E. P. Relações entre família e escola e suas implicações de gênero. Cadernos de Pesquisa, v. 110, p. 143-155, 2000. Disponível em: < $\underline{\mathrm{http}} / / \mathrm{www} . \mathrm{scielo} . \mathrm{br} / \mathrm{pdf} / \mathrm{cp} / \mathrm{n} 110 /$ n110a06.pdf>. Acesso em 04 de novembro de 2014.

COSTA, J. A. Projetos educativos das escolas: um contributo para sua (des)construção. Educação \& Sociedade, Campinas, v. 24, n. 85?, p. 1319-1340, dez. 2003.

DIAS, T. T. (2009). Pesquisando a relação família-escola: o que revelam as teses e dissertações dos programas de pós-graduação brasileiros. Tese (Doutorado em Educação Escolar) - Programa de Pós-graduação em Educação Escolar, Universidade Estadual Paulista,

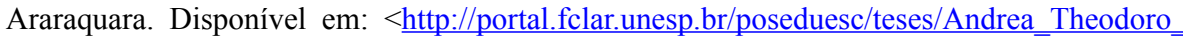
Toci Dias.pdf>. Acesso em 12 de agosto de 2014.

DIOGO, A. M.. Famílias e escolaridade: representações parentais da escolarização, classe social e dinâmica familiar. Lisboa: Edições Colibri, 1998

EPSTEIN, J. L. Parents' reaction to teacher practices of parent involvement. The Elementary School Journnal, v. 86, n. 3, p. 277-294, jan.1986.

FEVORINI, L. B. O envolvimento dos pais na educação escolar dos filhos: um estudo exploratório. Tese (Doutorado em Psicologia), Instituto de Psicologia, Universidade de São Paulo, 2009. 
FONSECA, M. Projeto Político Pedagógico e o Plano de Desenvolvimento da Escola: duas concepções antagônicas de gestão escolar. Caderno do CEDES, Campinas, v. 23, n. 61, p. 302-318, dez. 2003.

FRANCO, A. L. S. O conceito de relação, pensado a partir da relação entre o médico e o paciente. In: PETRINI, J. C.; CAVALCANTI, V. R. S. (Orgs.). Família, Sociedade e Subjetividades: uma perspectiva multidisciplinar. Petrópolis: Vozes, 2005, p. 225-239.

IANNACCONNE, A.; MARSICO, G. The Work of Schooling. In: VALSINER, J. (Ed.). Oxford Handbook of Culture and Psychology, New York: Oxford University Press, p. 830$868,2012$.

HERNÁNDEZ, A. M. S. A relação escola e família na opinião de seus agentes. Dissertação (Mestrado em Psicologia). Pontifícia Universidade Católica de Campinas, Campinas.1995.

LIBÂNEO, J. C. Pedagogia e Pedagogos, para quê? São Paulo: Cortez, 1998.

MARQUES, K. H. B.; SIGOLO, S. R. R. L. (). Comunicação e envolvimento: possibilidades e interconexões entre família-escola. Paidéia, Araraquara, v. 22, n. 51, p. 546-557, jan./abr. 2012. Disponível em: $<$ http://www.scielo.br/pdf/paideia/v22n51/11.pdf $>$. Acesso em 03 de out. de 2014 .

NEVES, D. S. Significações de pais e professores sobre a relação família-escola: as armadilhas de um (des)encontro. Tese (Doutorado em Psicologia). Universidade Federal da Bahia, Salvador 2014.

NOGUEIRA, M. A. A relação família-escola na contemporaneidade: fenômeno social/ interrogações sociológicas. Análise Social, Lisboa, v. XL, n. 176, out. 2005.

OLIVEIRA, A. R. Relação escola e famílias: visão de professores e mães de alunos de classes de recuperação paralela. Dissertação (Mestrado em Psicologia), Universidade Federal de São Carlos, São Carlos. (2004). Disponível em: < https://repositorio.ufscar.br/handle/ ufscar/2551? show=full > . Acesso em 19 de setembro de 2014.

OLIVEIRA, C. B. E. Psicologia escolar e a relação escola família no ensino médio: estudando as concepções desta relação. Dissertação (Mestrado em Psicologia). Universidade de Brasília-UnB. Brasília, DF. 2007. Disponível em: <http://bdtd.bce.unb.br/tedesimplificado/ tde arquivos/27/TDE-2007-11-28T104059Z-2073/Publico/Dissertacao\%20Cynthia \%20 Bisinoto.pdf>. Acesso em 11 de setembro de 2014.

OLIVEIRA, C. B. E; MARINHO-ARAÚJO, C. M. A relação família-escola: intersecções e desafios. Revista Estudos de Psicologia. Brasília, DF, v. 27, n. 1, p. 99-108. jan./mar., 2010. Disponível em: <http://www.scielo.br/pdf/estpsi/v27n1/v27n1a12.pdf>. Acesso em 14 de outubro de 2014.

PAIXÃO, L. P.. Compreendendo a escola na perspectiva das famílias. In: Müller, M. L. R.; Paixão, L. P.. Educação, diferenças e desigualdades. Cuiabá: Ed. Da FMT, pp. 57-81, 2006.

PERRENOUD, Ph. \& cols.. A Escola de A a Z, 26 maneiras de repensar a educação. Porto Alegre: Artmed, 2005. 
POLONIA, A. C.; DESSEN, M. A. Em busca de uma compreensão das relações entre família e escola. Psicologia Escolar e Educacional, Campinas, v. 9, n. 2, p. 303-312, dez. 2005.

REGO, T. C. Memórias de escola: cultura escolar e constituição de singularidades. Petrópolis, RJ: Vozes, 2003.

RIBEIRO, D. F. Os bastidores da relação escola-família. Tese (Doutorado em Psicologia), Programa de Pós-Graduação em Psicologia, Universidade de São Paulo, Ribeirão Preto. 2004. Disponível em: <http://www.teses.usp.br/teses/disponiveis/59/59137/tde-16072008-230443/ pt-br.php>. Acesso em 29 de agosto de 2014

RIBEIRO, D. F. ; ANDRADE, F. A. S. A assimetria na relação entre família e escola pública. Paidéia, v. 16, n. 35, 385-394, 2006. Disponível em: <http://www.scielo.br/pdf/paideia/v16n35/ v16n35a09.pdf>. Acesso em 10 de outubro de 2014.

ROMANELLI, G. Levantamento crítico sobre as relações entre família e escola, In: ROMANELLI, G.; NOGUEIRA, M. A; ZAGO, N. Família \& Escola. Petrópolis: Vozes, 2013, p. 29-82.

SANTOS, M. M. B. Em busca de escolas eficazes: a experiência de duas escolas em um município da Grande São Paulo e as relações escola-família. Dissertação de Mestrado, Universidade de São Paulo-USP. (2010). Disponível em: <http://www.teses.usp.br/teses/ disponiveis/48/48134/tde-11112010-162911/pt-br.php>. Acesso em 13 de outubro de 2015.

SILVA, P.. Escola-família: uma relação armadilha. Porto: Edições Afrontamento, 2003.

SILVA, P. Análise sociológica da relação escola-família: um roteiro sobre o caso português. Sociologia: Revista do Departamento de Sociologia da FLUP, v. 20, p. 443-464, 2010.

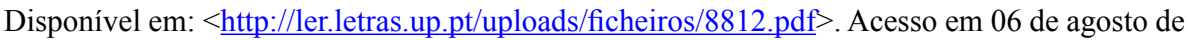
2014.

SILVA, M. de L. G.; CAVALCANTE, L. M. Relação família-escola: as contribuições da família no processo pedagógico vivido na educação infantil. Fórum Internacional de Pedagogia. Anais... Parnaíba, Piauí, 2012. Disponível em: <editorarealize.com.br/revistas/fiped/ trabalhos/7521662baf0ae9d3a041718d472f1c8b 1822.pdf>. Acesso em 03 de junho de 2015.

SILVEIRA, L. M. O. B.; WAGNER, A. Relação família-escola: práticas educativas utilizadas por pais e professores. Revista Psicologia Escolar e Educacional, Campinas, v. 13, n. 2, p. 283-291, jul./dez., 2009. Disponível em: <http://pepsic.bvsalud.org/scielo.php?script=sci arttext\&pid=S1413-85572009000200011 > . Acesso em 10 de outubro de 2014.

SZYMANSKI, H. A relação família-escola: desafios e perspectivas. Brasília: Plano, 2001.

TANCREDI, R. M. S. P.; REALY, A. M. M. R. Visões de professores sobre seus alunos: um estudo na área da educação infantil. In: Reunião Anual da Anped. 24. 2001. Caxambu. Anais... Disponível em: $<\underline{\text { http://24reuniao.anped.org.br/tp.htm> }}$. Acesso em 18 de agosto de 2014.

THIN, D. Famílias populares e instituição escolar: entre autonomia e heteronomia. Educação e Pesquisa, São Paulo, v. 36, n. spe, abr. 2010. Disponível em: $<\underline{\text { http: } / / w w w . s c i e l o . b r / s c i e l o . ~}$ 
php? script $=$ sci arttext\&pid $=\mathrm{S} 1517-97022010000400006 \& \operatorname{lng}=\mathrm{en} \& \mathrm{nrm}=\mathrm{iso}>$. Acesso em 05 agos. 2014. http://dx.doi.org/10.1590/S1517-97022010000400006.

SÁ, V. Racionalidades e práticas na gestão pedagógica: o caso do diretor de turma. 1 . ed. Coleção Ciências da Educação. Instituto de Inovação Educacional. 1997. Disponível em: $\quad<$ http://biblioteca.esec.pt/Opac/Pages/Search/Results.aspx? Database=10200 GLOBAL\&SearchText=AUT=\%22S\%C3\%A1,\%20Virg $\%$ C3\%ADnio $\% 20 \mathrm{de} \% 22>$. Acesso em 13 de novembro de 2014.

Submissão em: 25/02/2015

Aceite em: 27/12/2016

Fábio Kalil Souza é pedagogo do Instituto Federal de Educação, Ciência e Tecnologia de Sergipe, mestre em Educação pela Universidade Federal da Bahia-UFBA. Endereço: Rua Tobias Barreto, n. 538, Centro. Lagarto/SE, Brasil. CEP 494000-000 E-mail: fabioksouza@gmail.com 